dehiscence of the prosthesis only in cases of mucoid degeneration. ${ }^{3}$ Recently another case has been described by L. J. McCarthy and P. L. Wolf in a man aged $70^{4}$ who had had a murmur for at least 20 years previously. He was admitted in heart failure with severe mitral incompetence, and a valvular replacement was performed. He died four days later with a cerebral infarct. The excised mitral valve contained pools of blue mucoid material.

Mucoid degeneration of the heart valves has long been recognized as an association of Marfan's syndrome, ${ }^{15}$ but it is much less common than Erdheim's cystic medionecrosis of the aorta, which predisposes to dissecting aneurysm. In some of the cases of isolated mucoid degeneration there have been stigmata of Martin's sydrome, ${ }^{15}$ notably some skeletal manifestations. These presumably represent a forme fruste of the syndrome. In many others, including that of McCarthy and Wolf, there were no such stigmata, and the lesion appears to be a localized disorder of the valvular connective tissue.

This condition is not as uncommon as would appear from its infrequent description. In one series of 140 patients who had had one or more valves excised between the years 1961 and 1967 there were 21 cases of mucoid degeneration. ${ }^{6}$ It is also a predisposing factor to infective endocarditis. ${ }^{1}$ These considerations and the troubles that may follow valvular replacement make mucoid degeneration a lesion to be watched for by surgeon and pathologist.

' Read, R. C., Thal, A. P., and Wendt, V. E., Circulation, 1965, $32,897$. 2 Castleman, B., and McNeely, B. U., New England fournal of Medicine, $1967,277,92$.

${ }^{3}$ Wolf, P. L., and Read, R. C., American fournal of Clinical Pathology, $1964,42,518$.

- McCarthy, L. J., and Wolf, P. L., American fournal of Clinical Pathology, 1970, 54, 852. s McKusick, V. A., Heritable Disorders of Connective Tissue, 3rd edn,

- Frable, W. J., American fournal of Clinical Pathology, 1969, 52, 84.

\section{Ocular Bobbing}

In the Brave New Medical World of double-blind trials and parameters we are apt to look back wistfully to those halcyon days when simple clinical observation was all that mattered, when the wiseacre at the bedside could notice something out of the ordinary, and then immortalize his finding (and often his name) for posterity. And around the eyes, which are so often the signpost to the body's ills, a host of signs and syndromes (with unforgettable or all too easily forgettable eponyms) have accumulated over the last decades. So the recent description of "ocular bobbing" is an echo of this hallowed tradition.

Ocular bobbing is a distinctive, spontaneous eye movement having an abrupt, spontaneous downward jerk of the eyes and a slow return to the mid-position. It is readily distinguishable from the down-beating nystagmus (with the opposite slow-fast sequence) and the pendular movements of an ocular myoclonus. C. M. Fisher ${ }^{1}$ first described it ten years ago in patients with paralysis of horizontal conjugate eye movements. Four subsequent observers have added to the literature, which now musters 25 cases. The latest report, by $J$. $O$. Susac and colleagues ${ }^{2}$ subdivides bobbing into the "typical" form, "monocular" form (having a coexisting ocular palsy), and an "atypical" form, and will doubtless help to establish the condition as a clinical entity for the textbooks and examinations of the future.
The importance of this curious anomaly remains uncertain. It is usually noted in patients who are moribund (from intrapontine haemorrhage or similarly grave disorders) if not actually in their terminal coma, and its mechanism is obscure. But further cases will surely be reported, and so we may learn more about it. Any reminder of the value of plain clinical observation must always be welcome.

1 Fisher, C. M., in Pathogenesis and Treatment of Cerebrovascular Disease. A symposium edited by W. S. Fields. Illinois, Thomas, 1961 . Susac, J. O., Hoyt, W. F., Daroff, R. B., and Lawrence, W., foumal of Neurology, Neurosurgery and Psychiatry, 1970, 33, 771."

\section{Dermatitis Herpetiformis}

Job "took a potsherd to scrape himself withal." Though we may suspect, in view of his many troubles, that he was suffering from disseminated neurodermatitis with severe secondary infection, dermatitis herpetiformis has been suggested as a possible diagnosis. This too may have been the disease that caused Marat to spend so much of his time in the bath where Charlotte Corday stabbed him.

Dermatitis herpetiformis is a comparatively uncommon skin disease, but it deserves attention because of its favourable response to certain drugs and because the mucosa of the small intestine is often atrophic. Itch is the predominant symptom. It can reach an unbearable intensity, destroy sleep, embarrass its victim by making him scratch in public, and render him miserable and demoralized. The eruption appears in symmetrical patches-for example, over the shoulders, buttocks, elbows, and thighs. Within each patch are commonly a variety of lesions-weals, papules, vesicles, or bullae, scratch marks (often complicated by secondary pyogenic infection), pigmentation, and the scars of healed lesions. It is unusual to find a patient with dermatitis herpetiformis in whom vesicles or bullae do not appear at some time during the course of his disease. In children the blisters can be large and grouped round the mouth and genital region.

A common error in diagnosis is scabies. Other infestations must also be excluded, and onchocerciasis is a possibility in patients who have lived in those parts of the tropics where it is endemic.

Dapsone or sulphapyridine by mouth will suppress the lesions within a week, but they will recur when the dose falls below an optimal level that must be determined for each patient. Satisfactory control depends on carefully supervised treatment. The suppressive dose usually falls gradually over a course of years, and it may be possible to stop treatment altogether eventually. Though inorganic arsenic-for example, Fowler's solution-also clears the lesions, it is unsafe to give because of the risk of long-delayed serious effects such as cirrhosis of the liver and carcinoma. If the patient does not respond to treatment, the diagnosis should be reviewed with special reference to chronic liver or kidney disease, reticulosis, occult carcinoma, or disseminated neurodermatitis.

The aetiology of the disease remains obscure. The suppressive action of sulphapyridine does not depend on its antibacterial activity. The eruption will reappear promptly after years of suppression if the treatment is stopped, and it is interesting that under these circumstances the blisters may be unusually large. These drugs may block some metabolic pathway on which the eruption of lesions depends. The discovery that enteropathy can accompany dermatitis herpeti- 
formis has deepened the mystery. The enteropathy is glutendependent, but a gluten-free diet improves the eruption only in a minority of patients ${ }^{1}$. Conversely, suppression of the lesions with dapsone does not benefit the enteropathy. ${ }^{2}$

Owing to the recorded association of the disease with thyrotoxicosis and pernicious anaemia N. G. Fraser ${ }^{3}$ sought autoantibodies in the sera of patients with dermatitis herpetiformis. He found thyroid antibodies to be commoner and gastric antibodies not significantly commoner than in controls. His conclusion is that the disease is unlikely to result directly from autoantibody developed against the skin, but he thinks nevertheless that the skin lesions may depend on some kind of immunological reaction. O. C. Pock-Steen and A-M. Niordson ${ }^{4}$ described a patient suffering from gluten enteropathy. When she was given milk with a gluten-free diet she developed dermatitis herpetiformis, which disappeared when milk was withdrawn, only to reappear when milk was reintroduced. (Fraser had encountered a similar patient previously.) The immunoglobulins, especially IgM, tended to be raised during periods of milk ingestion. J. O'D. Alexander and colleagues 5 investigated the absorption and excretion of labelled dapsone in patients with dermatitis herpetiformis and controls. They showed that dapsone was not concentrated preferentially in skin lesions, that it was metabolized normally in patients with dermatitis herpetiformis, and that the enteropathy of this disease did not interfere with the absorption of the drug.

Thus no clear aetiological hypothesis is possible at this stage, but the two most promising lines of inquiry seem to be immunological and pharmacological. Perhaps more attention should be focused on the old observation that patients with dermatitis herpetiformis are often hypersensitive to ingested halogens.

\footnotetext{
' Marks, R., and Whittle, M. W., British Medical fournal, 1969, 4, 772. British Fournal of Dermatology, 1969, 81, 228

3 Fraser, N. G., British Fournal of Dermatology, 1970, 83, 609.

- Pock-Steen, O. C., Niordson, A-M., British fournal of Dermatology, $1970,83,614$.

${ }^{5}$ Alexander, J. O'D., et al., British fournal of Dermatology, 1970, 83, 620.
}

\section{Hooligans and Vandals}

In a paper presented recently to the Medico-Legal Society, T. C. N. Gibbens ${ }^{1}$ discusses some interesting aspects of the disturbances caused to society by hooligans and vandals. The epidemiology of such behaviour is incomplete for two reasons. Firstly, doctors see few hooligans or vandals, and they are only rarely arrested or detected. Secondly, because of the end results the social aspects overshadow medical or psychological factors. Several local authorities are taking active steps to try to deal with this problem, and it would seem advisable for the medical officer of health and an interested consultant psychiatrist to be included on their advisory committee.

The tendency to hooliganism is not abnormal in human behaviour. In fact, it is only when it extends beyond acceptable limits that it becomes reprehensible. The borderline between high spirits in a group of young people and rowdyism leading to actual violence is small. Many group impulses for demonstration are natural, and it is only when they get out of hand that they are unacceptable to society. Drunkenness does not play a large part, especially in football rowdyism among youths. There seems to be a tradition in some forms of violent behaviour, as is shown by the antagonism which exists between supporters of certain football teams. Though rugby and cricket are the centre of much less hooliganism than is soccer owing to the different type of spectators at rugby matches and the less exciting pace of cricket, yet scenes of near hooligan behaviour have recently been witnessed at both. Hooliganism can in fact occur among any class in the community, but the magnitude of the crowds at football matches undoubtedly produces more scope for them to get away with their antisocial acts. These may vary from gang fights to frightening and molesting frail and ageing people who cannot protect themselves. The buliy boys have existed in all ages and cultures, and the behaviour patterns have similarities.

Much of the crowd behaviour at football matches, such as singing and scarf waving, is innocuous, but with a small minority it is the prelude to violence or vandalism which tends to bring excessive disrepute to many gatherings of people. The 50,000 soccer fans who go home quietly after the match are not news, but the dozen skinheads who have a fight make the headlines. It is particularly interesting to observe how the police have developed in present conditions probably the most effective means of control of mass rowdyism. They do not try to compete with threats and violence, but exercise forbearance and firm restraint often in the face of considerable provocation. But at the end of the day they are almost invariably the victors, as mass hooliganism is effective only so long as the gang and its ringleaders are together. Once the members are separated the emotional stimulus rapidly diminishes.

When we come to consider the equally important problem of vandalism-namely, the destruction of property rather than personal violence-we again see a common form of behaviour carried to excess. Children like to break things and there can be some satisfaction in destruction. Moreover the broken objects attract attention. So the hooligan who takes to vandalism leaves behind a trail of destruction and annoyance, but still preserves his anonymity. This type of behaviour takes a number of forms-from the senseless, such as defacing telephone boxes or railway compartments, to the wilfully and criminally destructive, as illustrated by arson. It may be political with writing up of slogans or painting statues, or acquisitive, varying from souvenir hunting to actual thieving; or again it may be vindictive to pay back some score against an individual or society.

Whatever the background, hooligans and vandals throw extra stress on many of the community services. In the health field probably the most immediately involved are the ambulance services. They are regularly called to the scenes of such episodes, and while they may have to work in difficult surroundings it is of some interest that there is no record of an ambulance crew ever having been molested. But damage to telephones can have serious consequences in making medical aid difficult to summon. Damage to other services, such as disruption or contamination of water supplies, can equally endanger the lives of innocent people and often serve to harden resistance against the vandals' cause.

As Gibbens indicates, the real hope of diminishing such disorderly behaviour lies in a better quality of family life, a greater effort by parents to understand their children and to co-operate with them in creating a socially adjusted community.

\footnotetext{
Gibbens, T. C. N. Medico-Legal fournal, 1970, 38, 122
} 